Acta Crystallographica Section E

Structure Reports

Online

ISSN 1600-5368

\title{
(2E)-3-(Biphenyl-4-yl)-1-(4-methoxyphenyl)- prop-2-en-1-one
}

The title compound, $\mathrm{C}_{22} \mathrm{H}_{18} \mathrm{O}_{2}$, was prepared from biphenyl-4carbaldehyde and 4-methoxyacetophenone. The molecule deviates significantly from planarity.

\section{Comment}

Inorganic Chemistry, School of Chemical Science and Engineering, Royal Institute of Technology (KTH), 10044 Stockholm, Sweden,

${ }^{\mathbf{b}}$ Department of Studies in Chemistry, University of Mysore, Manasagangotri, Mysore 570006 India, ${ }^{\mathbf{c}}$ Department of Chemistry, Mangalore University, Mangalagangotri 574 199, India, and ${ }^{\mathbf{d}}$ Department of Chemistry, P. A. College of Engineering, Nadupadavu, Mangalore 574 153, India

Correspondence e-mail: afischer@kth.se

\section{Key indicators}

Single-crystal X-ray study

$T=296 \mathrm{~K}$

Mean $\sigma(\mathrm{C}-\mathrm{C})=0.006 \AA$

$R$ factor $=0.057$

$w R$ factor $=0.145$

Data-to-parameter ratio $=8.5$

For details of how these key indicators were automatically derived from the article, see http://journals.iucr.org/e.

For a structurally simple group of compounds, chalcones have displayed an impressive array of biological activities, among which antimalarial (Liu et al., 2003), antiprotozoal (Nielson et al., 1998), nitric oxide inhibition (Rajas et al., 2002) and anticancer activities (Dinkova-Kostova et al., 1998) have been cited in the literature. Among several organic compounds reported for non-linear optical (NLO) properties, chalcone derivatives are notable materials for their excellent blue-light transmittance and good crystallizability. They provide the necessary configuration to show NLO properties, with two planar rings connected through a conjugated double bond (Goto et al., 1991; Uchida et al., 1998; Tam et al., 1989; Indira et al., 2002, Sarojini et al., 2006). Substitution on either of the benzene rings greatly influences the non-centrosymmetric crystal packing. It is speculated that, in order to improve the activity, more bulky substituents should be introduced to increase the spontaneous polarization of non-centrosymmetric crystals (Fichou et al., 1988). The molecular hyperpolarizability is strongly influenced, not only by the electronic effect, but also by the steric effect of the substituent (Cho et al., 1996). Prompted by this, and in a continuation of our quest to synthesize new materials which can find use in the photonics industry, we have synthesized new chalcones and studied their SHG (second harmonic generation) efficiency. In a continuation of our work on chalcones (Harrison et al., 2005; Harrison, Yathirajan, Sarojini, Narayana \& Vijaya Raj, 2006; Harrison, Yathirajan, Sarojini, Narayana \& Indira, 2006; Harrison, Yathirajan, Anilkumar et al., 2006), the present paper reports the crystal structure of a newly synthesized chalcone, (I), which was synthesized from biphenyl-4-carbaldehyde and 4methoxyacetophenone.

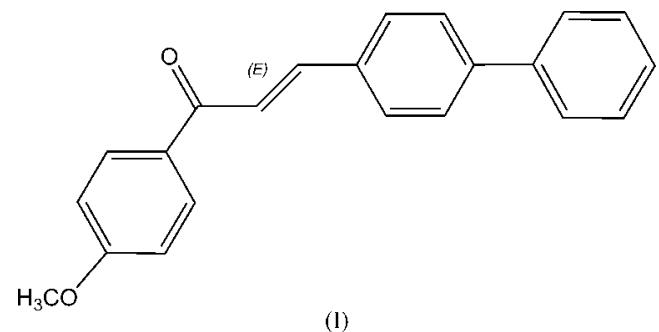

Fig. 1 shows the molecular structure of (I). The geometry of the molecule is unexceptional. The molecule deviates signifi- 
cantly from planarity, with dihedral angles of $8.51(13)^{\circ}$ between the rings of the biphenyl group and $54.14(12)^{\circ}$ between the $\mathrm{C} 7-\mathrm{C} 12$ ring and the $\mathrm{C} 16-\mathrm{C} 21$ ring.

\section{Experimental}

4-Methoxyacetophenone $(1.5 \mathrm{~g}, 0.01 \mathrm{~mol})$ in methanol $(20 \mathrm{ml})$ was mixed with biphenyl-4-carbaldehyde $(1.82 \mathrm{~g}, 0.01 \mathrm{~mol})$ and the mixture was treated with $30 \%$ potassium hydroxide solution $(3 \mathrm{ml})$ at $278 \mathrm{~K}$. The reaction mixture was then brought to room temperature and stirred for $3 \mathrm{~h}$. The solid precipate was filtered off, washed with water, dried and recrystallized from acetone (m.p. 419-421 K). Analysis (\%) for $\mathrm{C}_{22} \mathrm{H}_{18} \mathrm{O}_{2}$ found (calculated): $\mathrm{C} 83.94$ (84.05), $\mathrm{H} 5.66$ (5.77).

\section{Crystal data}

$\mathrm{C}_{22} \mathrm{H}_{18} \mathrm{O}_{2}$

$M_{r}=314.38$

Monoclinic, $C c$ $a=35.232(3) \AA$

$b=7.4972(5) \AA$

$c=6.2113(3) \AA$

$\beta=95.509(6)^{\circ}$

$$
\begin{aligned}
& V=1633.08(18) \AA^{3} \\
& Z=4 \\
& \text { Mo } K \alpha \text { radiation } \\
& \mu=0.08 \mathrm{~mm}^{-1} \\
& T=296 \mathrm{~K} \\
& 0.58 \times 0.33 \times 0.12 \mathrm{~mm}
\end{aligned}
$$

\section{Data collection}

Bruker-Nonius KappaCCD diffractometer

Absorption correction: none 10464 measured reflections

\section{Refinement}

$R\left[F^{2}>2 \sigma\left(F^{2}\right)\right]=0.057$

$w R\left(F^{2}\right)=0.145$

$S=1.12$

1843 reflections
1843 independent reflections 1408 reflections with $I>2 \sigma(I)$ $R_{\text {int }}=0.048$
Due to the absence of significant anomalous dispersion effects, Friedel pairs were merged prior to refinement. $\mathrm{H}$ atoms were placed at calculated positions and refined as riding on the respective carrier atom, with $\mathrm{C}-\mathrm{H}=0.93 \AA$ and $U_{\text {iso }}(\mathrm{H})=1.2 U_{\text {eq }}(\mathrm{C})$ for $C s p^{2}$ or $\mathrm{C}-\mathrm{H}$ $=0.96 \AA$ and $U_{\text {iso }}(\mathrm{H})=1.5 U_{\text {eq }}(\mathrm{C})$ for methyl $\mathrm{H}$ atoms.

Data collection: COLLECT (Nonius, 1999); cell refinement: DIRAX/LSQ (Duisenberg, 1992); data reduction: EVALCCD (Duisenberg et al., 2003); program(s) used to solve structure: SHELXS97 (Sheldrick, 1997); program(s) used to refine structure: SHELXL97 (Sheldrick, 1997); molecular graphics: DIAMOND (Brandenburg, 2006); software used to prepare material for publication: publCIF (Westrip, 2007).

One of the authors (BKS) thanks AICTE, Government of India, for financial assistance through the Career Award for Young Teacher's Scheme, and BVA thanks Mangalore University for permission to carry out the research work. The

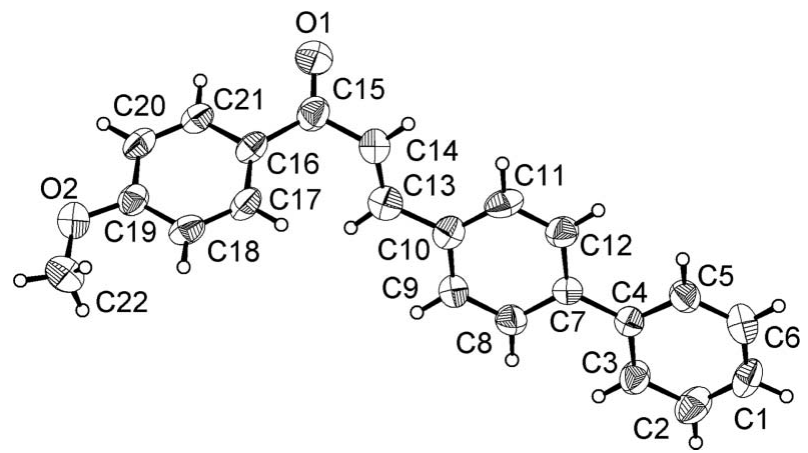

Figure 1

The molecular structure of the title compound. Displacement ellipsoids are drawn at the $50 \%$ probability level.

Swedish Research Council (VR) is acknowledged for providing funding for the single-crystal diffractometer.

\section{References}

Brandenburg, K. (2006). DIAMOND. Release 3.1d. Crystal Impact GbR, Bonn, Germany.

Cho, B. R., Je, J. T., Kim, H. S., Jean, S. J., Song, O. K. \& Wang, C. H. (1996). Bull. Korean Chem. Soc. 17, 693-695.

Dinkova-Kostova, A. T., Abey-Gunawardana, C. \& Talalay, P. (1998). J. Med. Chem. 41, 5287-5296.

Duisenberg, A. J. M. (1992). J. Appl. Cryst. 25, 92-96.

Duisenberg, A. J. M., Kroon-Batenburg, L. M. J. \& Schreurs, A. M. M. (2003). J. Appl. Cryst. 36, 220-229.

Fichou, D., Watanabe, T., Takeda, T., Miyata, S., Goto, Y. \& Nakayama, M. (1988). Jpn. J. Appl. Phys. 27, 429-430.

Goto, Y., Hayashi, A., Kimura, Y. \& Nakayama, M. (1991). J. Cryst. Growth, 108, 688-698.

Harrison, W. T. A., Yathirajan, H. S., Anilkumar, H. G., Sarojini, B. K. \& Narayana, B. (2006). Acta Cryst. E62, o3251-03253.

Harrison, W. T. A., Yathirajan, H. S., Sarojini, B. K., Narayana, B. \& Anilkumar, H. G. (2005). Acta Cryst. C61, o728-o730.

Harrison, W. T. A., Yathirajan, H. S., Sarojini, B. K., Narayana, B. \& Indira, J. (2006). Acta Cryst. E62, o1647-o1649.

Harrison, W. T. A., Yathirajan, H. S., Sarojini, B. K., Narayana, B. \& Vijaya Raj, K. K. (2006). Acta Cryst. E62, o1578-o1579.

Indira, J., Karat, P. P. \& Sarojini, B. K. (2002). J. Cryst. Growth, 242, 209-214.

Liu, M., Wilairat, P., Croft, S. L., Tan, A. L. C. \& Go, M. I. (2003). Bioorg. Med. Chem. 11, 2729-2738.

Nielson, S. F., Christensen, S. B., Cruciani, G., Kharazmi, A. \& Liljefors, T. (1998). J. Med. Chem. 41, 4819-4832.

Nonius (1999). COLLECT. Nonius BV, Delft, The Netherlands.

Rajas, J., Paya, M., Domingues, J. N. \& Ferrandiz, M. L. (2002). Bioorg. Med. Chem. Lett. 12, 1951-1954.

Sarojini, B. K., Narayana, B., Ashalatha, B. V., Indira, J. \& Lobo, K. J. (2006). J. Cryst. Growth, 295, 54-59.

Sheldrick, G. M. (1997). SHELXS97 and SHELXL97. University of Göttingen, Germany.

Tam, W., Guerin, B., Calabrese, J. C. \& Stevenson, S. H. (1989). Chem. Phys. Lett. 154, 93-96.

Uchida, T., Kozawa, K., Sakai, T., Aoki, M., Yoguchi, H., Abduryim, A. \& Watanabe, Y. (1998). Mol. Cryst. Liq. Cryst. 315, 135-140.

Westrip, S. P. (2007). publCIF. In preparation. 